\title{
FINANCIAL ARCHITECTURE AS THE BASE OF THE FINANCIAL SAFETY OF THE ENTERPRISE
}

\author{
Olga Sosnovska' ${ }^{1}$ Maksym Zhytar ${ }^{2}$
}

\begin{abstract}
In today's economic realities, achieving the necessary level of financial security of enterprises is a prerequisite for ensuring their sustainable operation and the formation of competitive development parameters in the internal and external market environment. The effectiveness of this process depends on building a high-quality financial architecture as the basic structural element of the company's financial security system. In this regard, the subject of the study is an analysis of existing theoretical approaches to the definition of financial architecture and its relationship with the financial security of the enterprise. The methodological basis of the research is the scientific development of domestic and foreign scientists, the fundamental theoretical positions of economic science in the field of financial architecture formation, financial risk management, and financial security of the enterprise. The purpose of the article is to study the essence of financial architecture in order to substantiate its determining influence on the financial security of the enterprise and ensure its sustainable functioning in an unstable development of economic processes. The article analyses the theoretical aspects of financial architecture and finds that the interpretation of this economic category is due to the existence of clear causal relationships between its constituent elements and their impact on the financial support. Proceeding from this, the definition of financial architecture is drawn as a set of interconnected structural elements such as capital structure, ownership structure and quality of corporate governance, which accumulate and mobilize financial resources, increase control over the activity of the enterprise, solve conflicts of interest between owners and other stakeholders. It is determined that the choice of principles and methods for constructing financial architecture depends on such financial interests of economic entities as forming a flexible financial potential, optimizing the structure of capital, increasing investment attractiveness, maximizing profits, and increasing the market value of the enterprise. It is proved that the result of building a flexible financial architecture is to provide the appropriate level of financial security of an enterprise by identifying, quantifying, neutralizing, minimizing, and monitoring its financial risks. It is proposed to systematize indicators of financial security level assessment on the most typical of its functional components, among which investment, credit, emission, innovation, and currency can be distinguished. It has been established that ensuring the appropriate level of financial security will contribute to achieving financial sustainability, forming qualitative financial potential, providing competitive advantages, harmonizing interests of economic entities, and creating an effective system of economic security of the enterprise. It is concluded that the construction of high-quality financial architecture is the basis of financial security of an enterprise, the level of which depends on the proper management of financial risks and ensuring an adequate level of safety of all its functional components. As a criterion for the effectiveness of the process of ensuring the financial security of the company, sustainable development of the enterprise was determined in the conditions of an unstable economic environment.
\end{abstract}

Key words: financial architecture, financial security, capital structure, ownership structure, quality of corporate governance, risk management.

JEL Classification: D04, A11, L22

\section{Introduction}

Taking into account the current tendencies of dynamism and uncertainty of economic processes, the ability of enterprises to efficiently conduct the economic activity and stable development is determined by

\footnotetext{
Corresponding author:

${ }^{1}$ Borys Grinchenko Kyiv University, Ukraine.

E-mail: sosnovska.oo@gmail.com

${ }^{2}$ University of the State Fiscal Service of Ukraine, Ukraine.

E-mail: zhytarmaksym@gmail.com
}

the level of their adaptation to internal and external parameters of functioning. Under these circumstances, the most priority task is to create an effective system of economic security of the enterprise to protect the business entities from the threats of a dangerous 
economic environment. In this case, the main and decisive functional component of this system is financial security, as evidenced by a significant number of existing scientific research in this scientific direction.

It should be noted that to the problems of providing financial security of enterprises, the works of such domestic and foreign scientists are devoted as J. C. Van Horne, T. Allison, G. Foster, J. Schumpeter, L. I. Abalkin, V. M. Heiets, O. I. Baranovskyi, I. O. Blank, T.G.Vasyltsiv, K.S.Horiacheva,L.I.Donets, Z.S.Varnalii, A. O. Yepifanov, M. M. Yermoshenko, S. M. Illiashenko, H. V. Kozachenko, and others. However, many issues are currently debatable and underdeveloped, requiring new scientific approaches to their solution. In this regard, the study of the essence of financial architecture as the basis of financial security of the enterprise is a topical issue.

The purpose of the article is to study the essence of financial architecture in order to substantiate its determining influence on the financial security of the enterprise and ensure its sustainable functioning in an unstable development of economic processes. To achieve the goal, the following is a prerequisite:

- analysis of theoretical approaches to the definition of financial architecture and the identification of its constituent elements;

- identification of the methodological link between financial architecture, financial security, and financial risks of the enterprise;

- selection of stages of management of financial risks of the enterprise;

- systematization of indicators for assessing the level of financial security as indicators of financial sustainability of the enterprise.

The scientific novelty of the research is the development of theoretical provisions for determining the methodological relationship between financial architecture and financial security, the achievement of which level depends on the process of management of financial risks of the enterprise to promote its sustainable functioning.

Theoretical and practical aspects offinancial architecture of companies was studied by many foreign scientists, among which are: M. Barclay, R. Brealey, C. Brigham, R. Vyshnia, H. Demsetz, T. Dolhopiatova, R. Entov, I. Ivashkivska, R. Kapeliushnykov M. Kokoreva, B. Kolass, R. La Porta, F. Lopez de Silanes, S. Myers, K. Smith, A. Stepanova, J. Finnerty, J. Van Horne, A. Shleifer, and others. Among scientists who studied labour issues can be noted: N. Bychkova, M. Bilyk, I. Blank, I. Ziatkovskyi, V. Melnyk, S. Onishko, O. Tereshchenko, A. Poddierohin, V. Fedosov, L. Fedulova, S. Yurii, and others.

\section{Definition of the essence of financial architecture}

In the most general form, "architecture" is an expression of the patterns of structure inherent in the system, the general plan or concept used to create it and, on the other hand, an abstract description of the system, its structure, components, and their interrelations (Grigoriev).

As for the term "financial architecture", for the first time, this term was proposed in 1999 by S. Myers (Myers, 1999) who defines the financial architecture of companies as a set of financial indicators such as ownership, legal form of business organization, incentives, sources financing, and risk-sharing mechanisms. He notes that corporate financial theory and practice developed within certain financial architecture, public corporations in countries such as the US and the UK, namely, countries with well-developed and safe markets. The scientist stressed that the financial architecture depends on active and persistent risk markets, which in turn is also dependent on adequate information such as financial reports, basic investor protection, continuity of contracts and law and justice.

In the continuation of S. Myers's works, foreign scholars M. Barclay and K. Smith in their work use the term "financial architecture" when considering corporate finance issues. They note that the financial architecture of enterprises is primarily determined by its investment opportunities (Barclay, 1996). Companies with a high ratio of market-to-book value to better use less borrowed capital compared to companies with low rates. In addition, the authors conclude that the size of the company has a systematic effect on its financial architecture, since large and small companies have different access to the market for debt capital, while small companies have access to short-term banklending, while large have the opportunity to attract government loans and long-term debt.

Foreign scholars D. Cassimon and P.-J. Engelen argue that in addition to investment opportunities, there are also institutional barriers that influence the formation of an optimal financial architecture for firms in the "new economy" in developing countries.

In the writings of the last ten years, the term "financial architecture" is often viewed in the macroeconomic sense of the world financial architecture, and the financial architecture at the micro level is insufficiently highlighted. Yes, V. M. Melnik, N. V. Bychkova (Melnik, Bychkova, 2012) and A. M. Stepanova (Stepanova, 2009) continue to justify the development of the concept of S. Myers and considers the financial architecture in terms of financial activity of business entities - from the point of view of the management of the structure of capital and its efficiency.

In the dissertation research, N. V. Bychkova argues that financial architecture is a set of interconnected components and structural characteristics of corporations such as organizational and legal form, capital structure, ownership structure, corporate governance, which determine the structure of the corporation's finances and is a tool for improving the financial performance of the entity in the context of the development of an appropriate financial policy to 
achieve the strategic objectives of such activities, taking into account the combination of external and internal factors of the idea of corporation (Bychkova, 2008).

Author S. V. Klimchuk presents financial architecture as a system of tools and instruments for managing financial relations that form a financial institution and proposes the use of the term "architectonics of financial space" as a system of effective spatial functioning of a financial mechanism, which enables to qualitatively capture this area by means of functional dependence of structural elements and levers of the financial system (Klimchuk, 2012). In this case, it is advisable to agree with the opinion of V. O. Kozlova, who believes that this definition narrows its significance to the implementation of the financial mechanism.

The financial architecture of the enterprise is determined due to the presence of clear causal relationships between its constituent elements and their impact on the financial support of its activities. Therefore, it is appropriate for the enterprise to understand the combination of interconnected structural elements such as capital structure, ownership structure, and quality of corporate governance that accumulate and mobilize financial resources, strengthen control over the activities of the enterprise, resolve conflicts of interest between owners and other stakeholders, and are the basis of its financial security.

\section{Characteristics of elements of the financial architecture of the enterprise}

The decisive stage in the construction of the financial architecture of the enterprise is the definition of its basis - the financial interests of economic entities, whose implementation plan is closely linked with the provision of an adequate level of financial security of the enterprise. Thus, in the conditions of financial and economic instability, the financial interests of economic entities will be directly related to the main objective of effective functioning of the enterprise, which in turn will have a significant methodological value for choosing the principles and mechanisms for building its financial architecture. The following models of the definition of the main goal of the enterprise are presented in the scientific literature: the model of profit maximization (based on the principles of the classical economic theory and the marginalist theory of the firm), the model of transaction cost minimization (based on theoretical principles of neo-institutionalism by R. Coase), the model of maximization of sales, growth of the enterprise, model of provision of competitive advantages, model of value-added maximization, and model of maximizing the market value of the enterprise (Blank, 2004). Each of the existing models is independent and offers a specific purpose of the company's operation, which may be a priority for a particular enterprise at different stages of its life cycle. At the same time, all target benchmarks are interconnected and each of them will influence the achievement of the main goal of effective operation of the enterprise and satisfaction of the financial interests of economic entities.

Determining the main goal of the operation of the enterprise is the basis for building its financial architecture. As the key elements of the financial architecture of the enterprise, it is appropriate to allocate: ownership structure, the capital structure of the enterprise, and the quality of corporate governance (Figure 1).

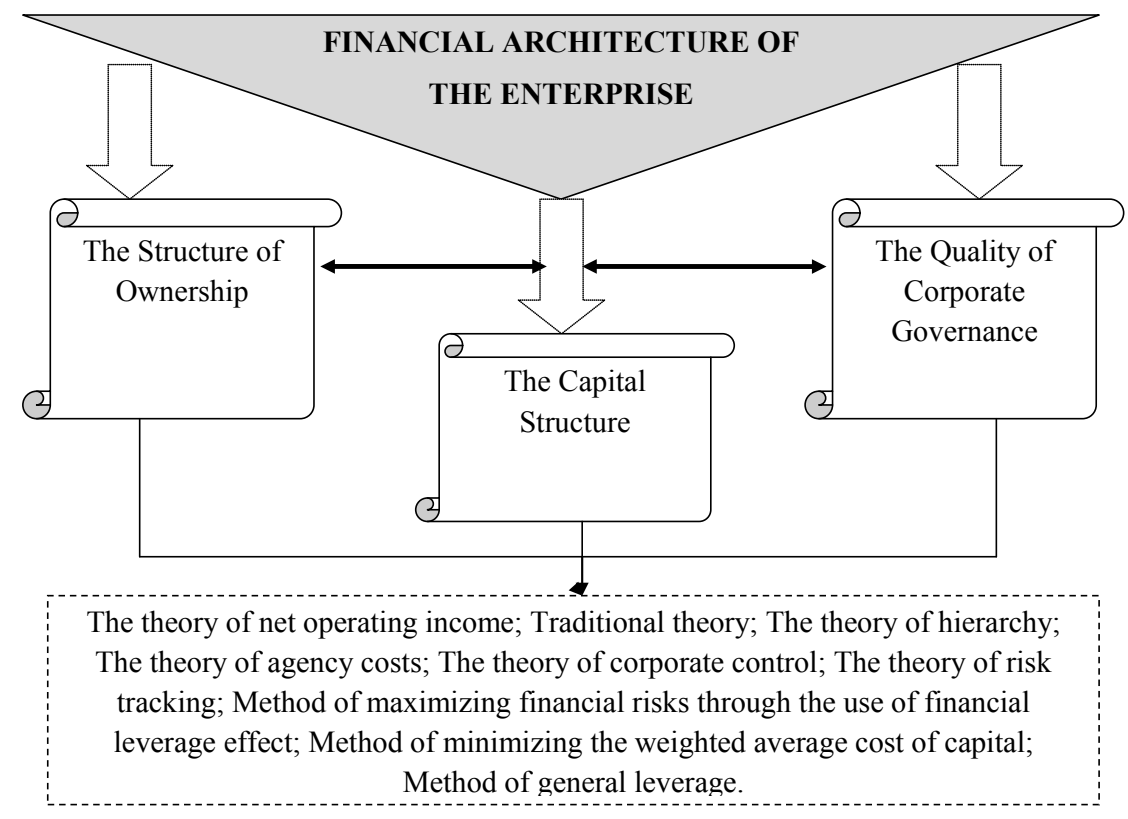

Figure 1. Elements of the financial architecture of the enterprise

Source: developed by the authors 
It must be agreed with many scholars who believe that the ownership structure should be considered through the prism of agency conflicts between managers and shareholders, majority and minority shareholders, state and private owners. The optimal ownership structure should facilitate, on the one hand, the concentration of capital in the hands of an effective owner and, on the other hand, the matching of the capital structure with the strategic goal of the enterprise.

The capital structure of an enterprise sets the risk distribution between investors, especially financial risks. Market imperfections (taxes, transaction and agency costs) lead to a dependence of the efficiency of the structure of capital, which suggests a negative impact of debt load on strategic efficiency. In addition, the formation of a sound capital structure through the implementation of high-tech innovative projects involves solving a number of tasks related to the assessment of sources of funding, the form of attraction, the degree of accessibility, the time of disposal, the cost of attracting a certain type of financial resources, financial risk, and other conditions attracting a specific source of innovation financing. Therefore, the key issue in the structure of capital is the assessment of the rationality of the ratio of individual groups of sources of financing for innovation and, first of all, own and borrowed capital, as well as substantiation of managerial decisions on the rational ratio of sources of funding for specific innovation projects. It should be noted that in Ukraine at the present stage, it is rather difficult to assess the ownership structure of the enterprise since it is rather opaque.

One of the main tasks of corporate governance is the minimization of transaction costs related to the delineation of rights and responsibilities of managers, as well as agency costs associated with the diverse interests of managers and the risk of shareholders. An assessment of the level of corporate governance is carried out to determine the appropriateness of management principles that are used in a particular enterprise - the generally accepted principles that underlie effective corporate governance and can be applied in a wide range of legal, economic, and political conditions. The final result of the assessment is the corporate governance rating that is assigned to the research object according to the National Rating scale of corporate governance ratings by the rating agency of the agency as a result of the voting. This component of the financial architecture of the enterprise is difficult to analyse since a significant part of enterprises do not provide information on their official sites.

\section{The methodological relationship between the financial architecture and financial security of the enterprise}

It should be noted that the process of forming the financial architecture of the enterprise occurs under the influence of a significant number of factors of the internal and external environment. Among them, financial factors are important, which include the provision of financial stability of enterprises and the growth of the market value of business through the effective formation and allocation of financial flows, which in turn characterizes the financial potential of the enterprise and ensures its liquidity and synchronization of financial flows in time and for volumes. The result of these factors may be the emergence of financial risks, the realization of which directly affects the financial security of the enterprise and leads to the positive or negative consequences of its activities.

It should be noted that in the vast majority of scientific studies, there is a correlation between the concepts of financial security and risk. We consider it the correct position because, in today's knowledge, knowledge of the risk category can significantly improve the efficiency of financial security management of the enterprise. We agree that the financial risk category regarding the provision of financial security of an enterprise includes two main components: identification and evaluation of risk, which is largely expert and probabilistic, and financial risk management in order to ensure the financial security of an enterprise and prevent its market value from falling (Yermoshenko, 2010). This is precisely the methodological link between financial architecture, financial security, and financial risk at the enterprise level. As is rightly noted by O. Shishkina, there is the growing relevance of the problem of risk management in the world, as evidenced by the establishment of the Institute of Risk Management (IRM), the Global Association of Risk Professionals, the International the International Risk Governance Council (IRGC), the Federation of European Risk Management Standards. The urgency of the problems in the field of risk management has led to the creation of risk management standards, which resulted from the joint efforts of the Institute of Risk Management (IRM), the Association of Risk Management and Insurance (AIRMIC), the National Risk Management Forum in the public sector (Shishkina, 2014).

In this regard, the necessary condition for maintaining an adequate level of financial security is the formation of a flexible financial architecture of the enterprise through effective management of its financial risks (Figure 2).

\section{Stages of management of financial risks of the enterprise}

In domestic science, the perception of the process of managing financial risk is based predominantly on foreign experience, which needs to be adapted to the current realities of the Ukrainian economy. Currently, financial risk management is a specific area of financial management, which in recent years has been treated as risk management in research. The process of financial risk management includes a defined sequence of management decisions, which in a systematic way 


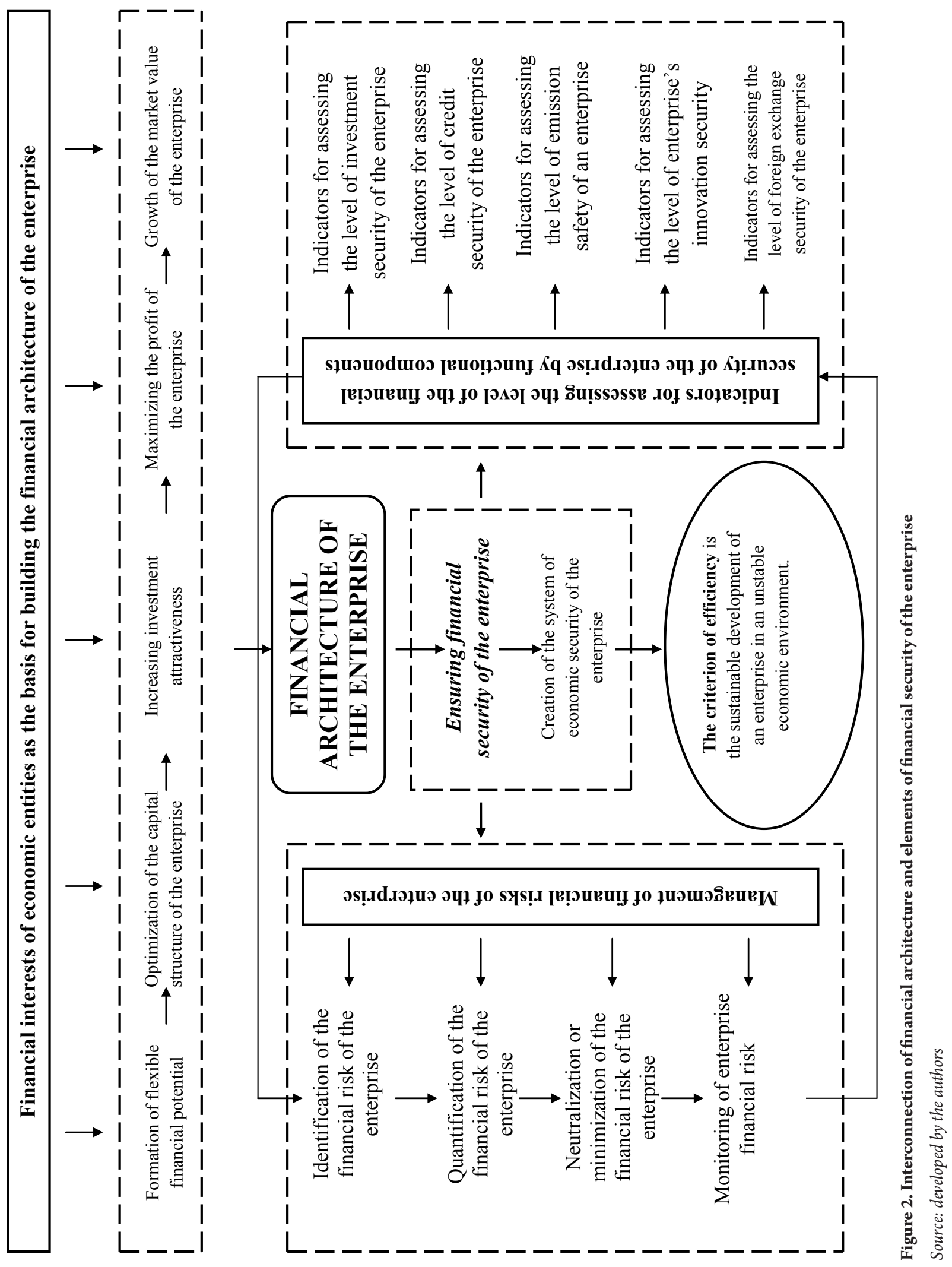


can be represented by such interconnected stages as identification, quantification, neutralization or minimization, and risk monitoring.

At the identification stage, a qualitative analysis of systematic and non-systematic financial risks of the enterprise is carried out by identifying internal and external risk factors and systematizing potential financial risks that are characteristic of the enterprise's economic activity at the appropriate stage of its life cycle. The most responsible and methodically complex stage of financial risk management is its quantification, which involves a quantitative assessment of the possible magnitude of risk and the calculation of the probability of occurrence of a negative event, the duration of the period of exposure to risk and the size of possible financial losses.

The formation of qualitative and quantitative data is the basis for the implementation of the phase of neutralization or minimization of risk through the use of known methods for avoiding, diversifying, hedging, distributing, limiting the concentration, insurance, and others.

The final stage of risk monitoring involves comparing the planned and projected values of financial security indicators of an enterprise with their thresholds, beyond which there is a change in the status of financial security - from safe to dangerous. Under these conditions, the financial architecture of the enterprise becomes more vulnerable and loses the ability to effectively adapt to the factors of a dynamic economic environment that results from a violation of the financial interests of economic entities.

\section{Systematization of indicators for assessing the level of financial security of enterprises}

Taking into account the aforementioned, a quantitative assessment of the level of financial security of an enterprise is possible provided that its indicators are monitored, the timely conduct of which helps to identify, quantify, and implement the methods of optimizing financial risks. It should be noted that a thorough analysis of the methods of assessing the financial security of an enterprise leads to the conclusion that there are different approaches to the choice of indicators of this process - from generally accepted indicators of the financial state of the enterprise to grouping indicators to assess the level of its financial security in accordance with various criteria. We believe that the choice of indicators for assessing the level of financial security of an enterprise should be carried out on its functional components with the possibility of a further definition of the integral index (Saati, 1993).

The most typical elements of the functional structure of financial security, which can be allocated at the enterprise level, should include investment (capital investment in the development of the enterprise), credit (formation and use of debt capital), issue (securities transactions), innovative (takes into account purely financial innovations), currency (export-import operations) and others. Certainly, the selected indicators of the level of financial security of an enterprise should be based on indicators characterizing the state of its financial activity. In addition, these indicators should meet the requirements of ease of calculation and comprehension, completeness and comprehensive coverage of the qualitative and quantitative state of financial security of the enterprise, the use of accounting and tax reporting for their calculation.

\section{Determination of the criterion of the financial safety of the enterprise}

Ensuring an appropriate level of financial security will help protect against financial risks of an unfavourable internal and external environment, achieving financial sustainability, developing a qualitative financial potential, ensuring competitive advantages, and harmonizing the financial interests of the enterprise. Achieving such results is the basis for creating an effective system of economic security of an enterprise, the optimal combination in the structure of which financial and other functional components, and their proper management will be the key to sustainable development of the enterprise in an unstable economic environment.

It will be appropriate to emphasize the fact that in the theory of systems, constancy is one of the main concepts that is determined when considering the behaviour of the system and implies the ability of the system to maintain its operation within the specified limits. From the standpoint of a systematic approach, the constancy of the system is determined by the mechanism of homeostasis, which is a process by which the system saves its parameters (state), in spite of changes in the external environment and acts as the most perfect form of self-regulation with the use of feedback. Violation of the system's stability means that there are divergent processes in it, that is, bifurcations that are not manageable and can lead to the disintegration of the system and its destruction (Wiener, 1951).

\section{Conclusions}

According to the results of the scientific research, the following conclusions can be drawn:

1. Based on the analysis of theoretical approaches, the definition of the financial architecture of the enterprise as a set of interconnected structural elements such as capital structure, ownership structure and quality of corporate management, which accumulate and mobilize financial resources, increase control over the activities of the enterprise, solve conflicts of interest between owners and other stakeholders.

2. The structure of capital, ownership structure and quality of corporate governance as components of the financial architecture of the enterprise have 
been characterized, which has allowed elaborating the concept of its essence and structure.

3. The methodological link between financial architecture and financial security of the enterprise is found, which is based on the dependence of the appropriate level of financial security and flexible financial architecture of the enterprise through the management of its financial risks.

4. The financial risks management stages, which include their identification, quantification, minimization or neutralization and monitoring, the consistent implementation of which will contribute to maintaining an adequate level of financial security and ensuring financial sustainability of the enterprise, are proposed.

5. The indicators of assessing the level of financial security on the investment, credit, emission, innovation, and currency functional components are systematized; observance of normative values is an important condition for ensuring financial stability and sustainable operation of the enterprise in an unstable economic environment.

Prospects for further research are the development of methodological approaches to enterprise risk management, the implementation of which will contribute to improving the financial architecture of the enterprise and increase its financial security.

\section{References:}

Grigoriev, L. Corporate Architecture and its Components. Innovative economy and organizational management. Retrieved from: http://bigc.ru/theory/innovations/corp_arch.php

Myers, S. (1999). Financial Architecture. European Financial Management, 5, 139.

Barclay, M. (1996). On Financial Architecture: Leverage, Maturity, And Priority. Journal of Applied Corporate Finance, 4, 4-17.

Legal and institutional barriers to optimal financial architecture for new economy firms in developing countries. Retrieved from: http://www.wider.unu.edu/stc/repec/pdfs/rp2002/dp2002-90.pdf

Melnyk, V. \& Bychkova, N. (2012). Financial architecture of national corporations and its influence on the efficiency of financial activities: monograph Aston, $244 \mathrm{p}$.

Stepanova, A. (2009). Influence of financial architecture of the company on its efficiency in conditions of growing capital markets: the author's abstract.... cand. econ. sciences. Moscow: State University Higher School of Economics. Bychkova, N. (2008). The Influence of Financial Architecture of National Corporations on the Effectiveness of Financial Activities: Author's Resume. dis for obtaining sciences. Degree Candidate econ Sciences: "Money, Finance and Credit". Kyiv, 22 p.

Klimchuk, S. (2012). Financial space and its integration priorities. The Economist News of Donbas, $2(28), 76-81$. Blank, I. (2004). Financial management of the enterprise, 784 p.

Yermoshenko, M. (2010). Financial component of economic security: state and enterprise: scientific monograph, National Academy of Management, $232 \mathrm{p}$.

Shishkina, O. (2014). Identification and express assessment of financial risks of industrial enterprises. Bulletin of the Chernihiv State Technological University. Series: Economic Sciences, 4(76), 238-246.

Wiener, N. (1951). Homeostasis in the Individual and Specialt. Journal of the Franklin (Praline) Institute, 251, 65-68.

Saati, T. (1993). Decision-making. The method of analyzing the hierarchy. Radio and Communication, 278 p.

Zhytar, M. O. (2017). The financial architecture of the corporation: the essence and components. Collection of scientific works of scientists and post-graduate students «Economic Herald of the University», 33/2, 370-374.

Sosnovskaya, O. (2018). Concept of economic safety of enterprise in the context of different methodological approaches. Business Inform, 3, 443-447. 